\title{
User Preferences for Accessing Publically Available Turfgrass Cultivar Performance Data
}

\author{
Chengyan Yue ${ }^{1}$, Jingjing Wang ${ }^{1}$, Eric Watkins ${ }^{1}$, Yiqun Xie ${ }^{1}$, \\ Shashi Shekhar ${ }^{1}$, Stacy A. Bonos ${ }^{2}$, Aaron Patton ${ }^{3}$, Kevin Morris ${ }^{4}$, \\ and Kristine Moncada ${ }^{1}$
}

\begin{abstract}
AdDitionAl Index words. genotype, National Turfgrass Evaluation Program, NTEP, variety

SUMMARY. Identifying sources of turfgrass cultivar performance data can be difficult for many consumers. Currently, the best source for data of this type is the National Turfgrass Evaluation Program (NTEP). Unfortunately, these data are made public in a format that is not readily usable for most consumers. Ideally, turfgrass cultivar data would be available in an easily accessible database. We conducted an online survey to investigate user preferences for accessing publically available turfgrass performance data in the United States. We found users desire a turfgrass cultivar performance database that allows for the identification of cultivars best adapted and tolerant to environmental stresses. The information on turfgrass mixtures and blends is also important to most users. Users' sociodemographic backgrounds, such as gender, education, occupation, and experience in the turf industry, affected their attitudes toward information provided in the turfgrass database. Turfgrass consumers need the new database to provide information on identifying turfgrass options that are resource efficient and endophyte resistant. Turfgrass breeders, researchers, and extension specialists use the turfgrass database to compare different turfgrasses cultivars to do further analysis. The results of this study provide important implications on how an updated turfgrass cultivar performance database and platform can fulfill the different needs of turfgrass researchers, extension personnel, breeders, and stakeholders.
\end{abstract}

$\mathrm{T}$ urfgrass is extensively used as a major landscape component covering an area larger than any other irrigated crop in the United States (Milesi et al., 2005). Residential and commercial lawns provide environmental, economic, and social benefits for society (Beard and Green, 1994). However, improper

Received for publication 23 Apr. 2019. Accepted for publication 20 June 2019.

Published online 27 August 2019.

${ }^{1}$ Department of Horticultural Science, University of Minnesota, 1970 Folwell Avenue, St. Paul, MN 55108

${ }^{2}$ Department of Plant Biology and Pathology, Rutgers University, 59 Dudley Road, Foran Hall, New Brunswick, NJ 08901

${ }^{3}$ Department of Horticulture and Landscape Architecture, Purdue University, West Lafayette, IN 47907

${ }^{4}$ National Turfgrass Evaluation Program, 10300 Baltimore Avenue, Beltsville, MD 20705

This research was funded by Specialty Crop Research Initiative Competitive Grant of the USDA's National Institute of Food and Agriculture (Grant number 2017-51181-27222: Increasing Low-Input Turfgrass Adoption though Breeding, Innovation, and Public Education).

C.Y. is the corresponding author. E-mail: yuechy@ umn.edu.

This is an open access article distributed under the CC BY-NC-ND license (https://creativecommons.org/ licenses/by-nc-nd/4.0/).

https://doi.org/10.21273/HORTTECH04390-19 management practice of turfgrass, for instance, overfertilization and excessive irrigation, can lead to negative impacts on the environment and human health (Martini et al., 2015; Milesi et al., 2005; Monaghan et al., 2016; Robbins and Birkenholtz, 2003; Robbins and Sharp, 2003). Selecting turfgrass cultivars that are both well adapted to site conditions and need fewer resources can help mitigate potential negative environmental impact. Therefore, acquiring useful information and knowledge on best turf management practices is essential to turf growers and managers.

Homeowners and public turf managers are the primary consumers and users of turfgrass seeds and sod (Beddow et al., 2001). For each turfgrass species, numerous cultivars are available (Christians et al., 2017). How they choose turfgrass cultivars and maintenance practices largely depends on their current turfgrass management knowledge (Yue et al., 2017a, 2017b). Numerous cultivars exhibit improved abiotic and biotic stress tolerance, as well as enhanced quality under limited inputs (Meyer et al., 2017). In spite of the development of low-input turfgrass cultivars, most consumers still have little awareness of the presence of these cultivars on the market (Yue et al., 2017b). Consumers also have a hard time finding reliable data sources and knowledge on turf maintenance. As previous studies suggested, turfgrass consumers trusted the information from the Cooperative Extension Service at local land-grant universities (Patton et al., 2013), but found information from the Internet as neither useful nor trustworthy (Yue et al., 2017a).

Turfgrass researchers have been collecting cultivar performance data for several decades, and typically these data are publically available on the Internet. The primary source of these data is the NTEP, which has been collecting data on major turfgrass species since the early 1980s. NTEP provides information of turfgrass features, such as quality, color, texture, density, uniformity, establishment, traffic tolerance, mowing quality, and resistance to abiotic and biotic stresses. NTEP data have been used by turfgrass researchers, extension specialists, turfgrass breeders and growers, and even some nonprofessional turfgrass consumers. However, the current data format is not userfriendly for average homeowners and other users. The NTEP website releases reports from replicated trials in a .txt file format that does not allow for the rapid queries to efficiently identify useful information. Moving NTEP and other publically available data to a modern relational database management system could make it easier for end users to get the latest and most useful information on major turfgrass species and cultivars. Possibly, users can also obtain data from future experiments that could assess the performance of turfgrass mixtures (mixtures of multiple species and cultivars) and blends (mixtures of cultivars from a single species).

\begin{tabular}{llll}
\hline $\begin{array}{l}\text { Units } \\
\text { To convert U.S. to SI, } \\
\text { multiply by }\end{array}$ & U.S. unit & SI unit & $\begin{array}{l}\text { To convert SI to U.S., } \\
\text { multiply by }\end{array}$ \\
\hline 0.4047 & $\mathrm{acre}(\mathrm{s})$ & $\mathrm{ha}$ & 2.4711 \\
0.4536 & $\mathrm{lb}$ & $\mathrm{kg}$ & 2.2046
\end{tabular}

Hortlechnology $\cdot$ October 2019 29(5) 
Table 1. Summary statistics of respondents' sociodemographic information from a survey investigating individual preference for turfgrass database use $(\mathrm{N}=306)$.

\begin{tabular}{|c|c|c|c|}
\hline Variable & Description $^{\mathrm{z}}$ & Mean & SD \\
\hline Age & $\begin{array}{l}\text { Age in category variable (years) } 1=18-30 ; 2=31- \\
\quad 40 ; 3=41-50 ; 4=51-60 ; 5=60 \text { or older }\end{array}$ & 3.40 & 1.28 \\
\hline Male & Dummy $=1$ if male; 0 otherwise & 0.92 & 0.27 \\
\hline Experience & $\begin{array}{l}\text { Years of experience working in the turfgrass } \\
\text { industry (years): } 1=5 \text { or less; } 2=6-10 ; 3=11- \\
15 ; 4=16-20 ; 5=21-30 ; 6=31 \text { or more }\end{array}$ & 4.50 & 1.56 \\
\hline Northeastern United States & $\begin{array}{l}\text { Dummy }=1 \text { if the respondent lives in the } \\
\text { northeastern United States; } 0=\text { otherwise }\end{array}$ & 0.18 & 0.39 \\
\hline Western United States & $\begin{array}{c}\text { Dummy }=1 \text { if the respondent lives in the } \\
\text { western United States; } 0=\text { otherwise }\end{array}$ & 0.12 & 0.32 \\
\hline Not United States & $\begin{array}{l}\text { Dummy }=1 \text { if the respondent does not reside } \\
\text { in the United States; } 0=\text { otherwise }\end{array}$ & 0.01 & 0.08 \\
\hline
\end{tabular}

Occupations

$\begin{array}{ll}\text { Golf course superintendent } & 28.10 \%\end{array}$

$\begin{array}{lr}\text { Sports turf manager } & 9.15 \%\end{array}$

$\begin{array}{lr}\text { Parks/grounds manager } & 8.82 \%\end{array}$

$\begin{array}{ll}\text { Lawn care operator } & 11.11 \%\end{array}$

$\begin{array}{ll}\text { Landscape management } & 8.50 \%\end{array}$

$\begin{array}{lr}\text { Sod production } & 5.23 \%\end{array}$

$\begin{array}{lr}\text { Research-public } & 10.13 \%\end{array}$

\begin{tabular}{lr} 
Research-private & $9.80 \%$ \\
\hline
\end{tabular}

$\begin{array}{lr}\text { Extension service } & 8.82 \%\end{array}$

$\begin{array}{lr}\text { Seed sales/supplier/seed broker } & 16.34 \%\end{array}$

$\begin{array}{ll}\text { Plant protectant sales } & 3.92 \%\end{array}$

$\begin{array}{lr}\text { Sales, other } & 5.56 \%\end{array}$

$\begin{array}{ll}\text { Lawn and garden supply } & 2.29 \%\end{array}$

\begin{tabular}{lr} 
Homeowner & $7.19 \%$ \\
\hline
\end{tabular}

$\begin{array}{lr}\text { Turfgrass breeder } & 4.90 \%\end{array}$

$\begin{array}{ll}\text { Property manager } & 4.25 \%\end{array}$

$\begin{array}{lr}\text { City or county administrator } & 0.65 \%\end{array}$

$\begin{array}{lr}\text { Local/county/state purchasing/ } & 0.98 \%\end{array}$ specification development

${ }_{\mathrm{z}}^{\mathrm{A}}$ dummy variable is a numerical variable used in regression analysis to distinguish different treatment groups.

Understanding the preference and needs of different users can help researchers improve the efficiency of data query and provide more valuable and reliable information. The focus of this study was to investigate the informational needs of different audiences of a turfgrass cultivar performance database. Specifically, our objectives were as follows: 1) to examine end-users' attitudes toward different usage options for a potential new turfgrass cultivar performance database, 2) to identify the most important information users need from a turfgrass cultivar performance database, 3 ) to determine preferences for data format and database features, and 4) to investigate how audiences from multiple disciplines use the database differently. We hope to provide information that can be used to build a useful, impactful turfgrass cultivar performance database so that stakeholders can more readily obtain research-based information when making seed purchasing decisions.

\section{Materials and methods}

An online survey was conducted to investigate individual preference for turfgrass database use. Survey participants with turfgrass experience were sought by contacting the members of 21 professional turfgrass organizations in Indiana, Wisconsin, New Jersey, 
Table 2. Summary statistics of respondents' attitudes toward different features/usages of a modern relational database management system of turfgrass cultivar performance data (on a seven-point Likert scale, with $1=$ "not at all likely" and $7=$ "extremely likely") from a survey investigating individual preference for turfgrass database use.

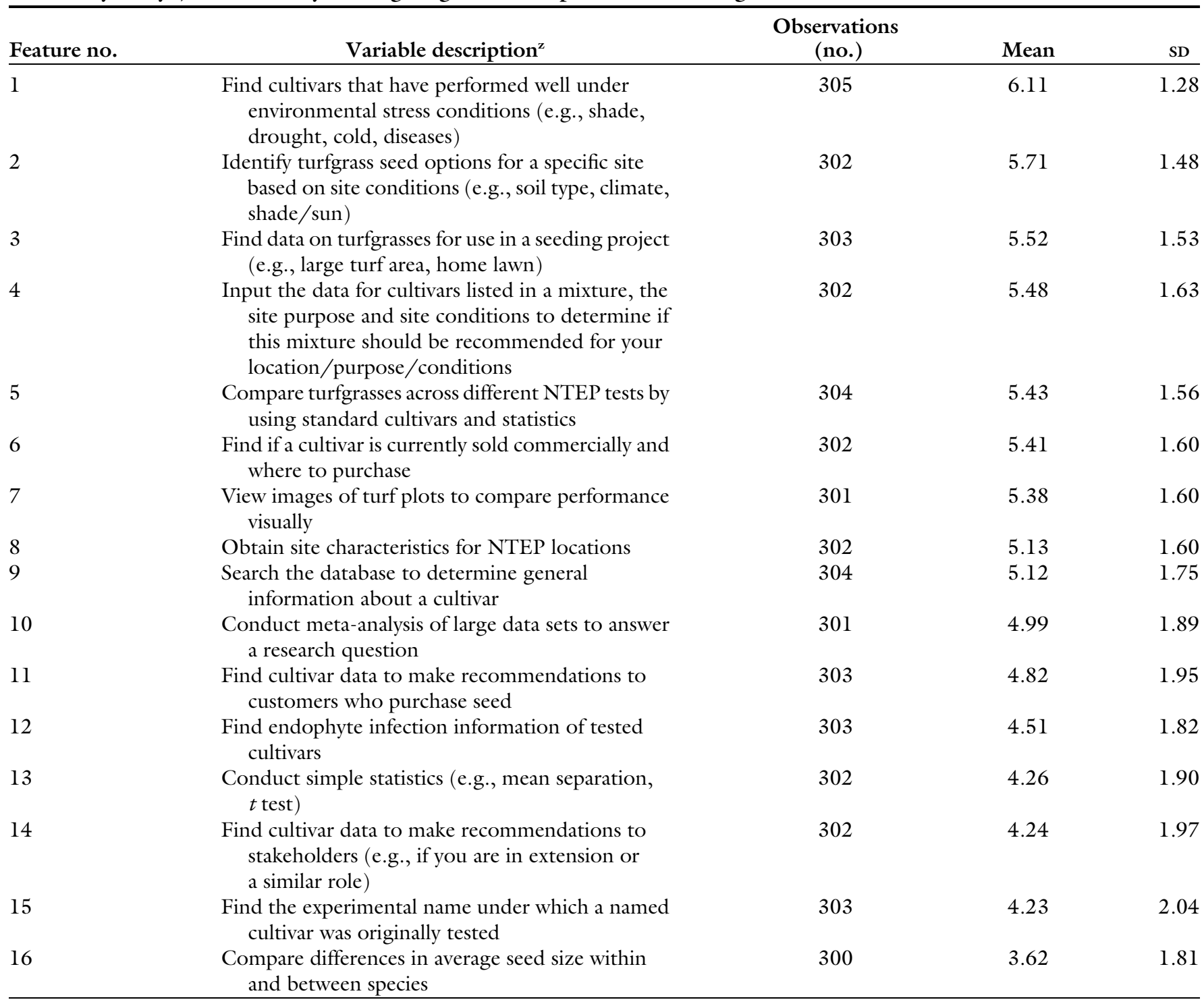

${ }^{\mathrm{z} N T E P}=$ National Turfgrass Evaluation Program.

Minnesota, and Oregon. These organizations included growers, landscapers, sport field managers, vendors, and educators in the turfgrass industry. The survey asked questions about participants' familiarity and current usage of NTEP data, such as the frequency of visiting the NTEP website. Questions also included individual attitudes toward different usages of a new turfgrass cultivar performance database, preferred wait time, desired data format, and interface. Demographic background information was collected, including respondents' age, gender, education level, state of residence, occupation, and, when applicable, regions of grass sales and years of experience working in the turfgrass industry.
In total, we obtained 443 responses, with 306 remaining after eliminating incomplete responses. The variables of our primary interest were self-reported attitudes toward different usage of a new NTEP database on a seven-point Likert scale (with a 1 to 7 continuous scale, $1=$ not at all likely, $2=$ unlikely, $3=$ somewhat unlikely, $4=$ neutral, $5=$ somewhat likely, $6=$ likely, and $7=$ extremely likely). Ordered probit models were used to analyze users' preferences for different NTEP database attributes. The ordered probit model has been widely used to identify the main factors affecting responses that were discrete and ordinal
(Greene and Hensher, 2010; Yue et al., 2010). Let $y_{i}^{*}$ be an unobservable, underlying latent variable representing respondent $i$ 's propensity to agree with a statement, and $y_{i}$ be an individual $i$ 's response to survey questions, which is the observed dependent variable. The unobserved dependent variable $y_{i}^{*}$ can be expressed as a function of a vector of independent variables $X$ by the following specification:

$$
y_{i}^{*}=X_{i} \beta+\varepsilon ; \varepsilon \sim \operatorname{Normal}(0,1),
$$

where $\beta$ is the vector of unknown coefficients and $\varepsilon$ are the error terms that are assumed to follow a normal distribution with zero mean and SD of 
Research Reports

Table 3. Summary statistics of respondents' experience and familiarity with National Turfgrass Evaluation Program (NTEP) website, preferred database features, and the sale volumes and turfgrass acreage for turf managers and sales from a survey investigating individual preference for turfgrass database use $(\mathrm{N}=306)$.

\section{Variables}

Internet

Heard

Visit frequency

Information useful

Data feature

Wait time

Download

Familiar_SQL

Familiar_GIS

Familiar_NTEP web

Familiar_Codebook NTEP

Option of data

\section{Description $^{\mathrm{z}}$}

Percentage of respondents who have ever used the internet to find turfgrass performance data before purchasing seeds

Percentage of respondents who have ever heard of NTEP before this survey

Frequency to visit the NTEP website to obtain cultivar evaluation information or results:

$$
0=\text { never }
$$

$1=$ less than once per year (only when needed)

$2=$ several times per year

$3=$ once per mo.

$1.31 \%$

$4=$ more than once per mo.

$7.84 \%$

$5=$ once per week

$1.96 \%$

$6=$ more than once per week

$3.59 \%$

$79.08 \%$

mixture performance information would be important

Important features of the NTEP data:

$1=$ not sure

2 = better format of analyzed data output (e.g., displayed in a figure instead of text file)

$3=$ increased speed for data availability (e.g., data are available on NTEP website soon after it has been collected in the field)

The duration of wait time for query processing resulting in the participant being dissatisfied with the database:

$1=10 \mathrm{~s}$ or less

$9.93 \%$

$2=10-60 \mathrm{~s}$

$3=$ more than $1 \mathrm{~min}$

$4=$ more than $5 \mathrm{~min}$

$39.74 \%$

$34.44 \%$

$15.89 \%$

$86.93 \%$

Percentage of participants who would be likely to download data from the NTEP website if that option was available in the future

Percentage of participant being familiar with SQL

Percentage of participant being familiar with GIS

$45.10 \%$

Percentage of participants being familiar with $67.32 \%$ NTEP website

Percentage of participant being familiar with codebook from the NTEP website

Option of data would increase use of NTEP data: $\mathrm{l}$ = raw data (not statistically analyzed) available for the previous collection year by 1 Mar. 2 = raw data available for download soon after being collected in the field (e.g., 1 to $2 \mathrm{~d}$ ), no analyzed data available

3 = analyzed data only reported one time per year

(e.g., by 1 Mar. the year after data collection) 4 = raw data available for download available soon after data collection, AND analyzed data reported one time per year (e.g., by 1 Mar. the year after data collection)

$5=$ none of these options would increase my use of NTEP data

Preferred query interface: 
Table 3. (Continued) Summary statistics of respondents' experience and familiarity with National Turfgrass Evaluation Program (NTEP) website, preferred database features, and the sale volumes and turfgrass acreage for turf managers and sales from a survey investigating individual preference for turfgrass database use $(\mathrm{N}=306)$.

\begin{tabular}{|c|c|c|}
\hline$\underline{\text { Variables }}$ & Description $^{\mathrm{z}}$ & Mean \\
\hline & $\begin{array}{l}\mathrm{l}=\text { Web-form (e.g., selecting a set of predefined } \\
\text { conditions) }\end{array}$ & $41.35 \%$ \\
\hline & $3=$ GIS or map-based (e.g., clicking a location) & $25.19 \%$ \\
\hline & $4=$ not sure & $30.83 \%$ \\
\hline \multirow[t]{3}{*}{ Output format } & Preferred query output format: & \\
\hline & $3=$ both & $66.79 \%$ \\
\hline & $4=$ not sure & $8.30 \%$ \\
\hline Other software & $\begin{array}{l}\text { Percentage to use the downloaded data in another } \\
\text { software }\end{array}$ & $42.16 \%$ \\
\hline Area & $\begin{array}{l}\text { The coverage a manager can manage (acres): } 1= \\
\text { less than } 1 ; 2=1-5 ; 3=5-10 ; 4=10-50 ; 5=50- \\
100 ; 6=\text { more than } 100\end{array}$ & 5.44 \\
\hline
\end{tabular}

${ }^{\mathrm{z}} \mathrm{SQL}=$ language used to communicate with a database; GIS = geographic information systems; 1 acre $=0.4047 \mathrm{ha} ; 1 \mathrm{lb}=0.4536 \mathrm{~kg}$.

1. The observed dependent variable $y$ is represented by

$$
y=\left\{\begin{array}{ccl}
1 & \text { if } & y^{*} \leq v_{1} \\
2 & \text { if } & v_{1} \leq y^{*} \leq v_{2} \\
& \vdots & \\
7 & \text { if } & y^{*} \geq v_{7}
\end{array}\right.
$$

The dependent variables include rated scales for usages such as to compare turfgrasses across different tests, or to find data on turfgrass for use in a seeding project. The independent variable vector $X$ includes information on individual characteristics, such as age, gender, education, regions of residence, regions of turfgrasses sales, years of working experience in the turf industry, and two dummy variables indicating if the respondent ever used the Internet to find information on turfgrass and ever heard of NTEP database.

\section{Results and discussion}

The summary statistics for demographics are listed in Table 1 . Most respondents were male, with an average age in the range of 41 to 50 years. The average education level was a 4-year college degree, and the average years of experience in the turfgrass industry were $\approx 16$ to 20 years. Approximately $30 \%$ of the respondents live in the midwestern United States, followed by the northeastern (18\%), southern (13\%), and western (11\%) United States. Twentyeight percent of the respondents were golf course superintendents and 16\% were seed sales/supplier/seed brokers. Groups of sport turf managers, parks/grounds managers, lawn care operators, and landscape managers each account for $9 \%$ to $11 \%$ of the sample. More than $9 \%$ of the respondents were from extension service, or public or private research institutes. Seven percent of the respondents were homeowners.

Table 2 shows the summary statistics for the seven-point Likert scale of different usage of a new turfgrass cultivar performance database. The most highly rated future use desired in a new database was to find betterperforming cultivars under environmentally stressed conditions. This feature was rated significantly higher than other features $(P<0.01)$, and more than $90 \%$ of the respondents were likely to need this information. Other important features include identifying turfgrass seed options for a specific site based on site conditions, finding data on turfgrasses for use in a seeding project (e.g., large turf area, home lawn), and inputting the data for cultivars listed in a mixture to determine if the mixture is suitable for a given location and purpose (Table 2).

Respondents had positive attitudes toward features such as comparing turfgrasses across different NTEP tests by using standard cultivars and statistics, finding if a cultivar is currently sold commercially and where to purchase, viewing images of turf plots to compare performance visually, obtaining site characteristics for NTEP locations, and searching the database to determine general information about specific cultivars (Table 2). On average, respondents had neutral attitudes toward using the database to conduct meta-analyses of large data sets to answer a research question, finding cultivar data to make recommendations to customers who purchase seed, finding endophyte infection information of tested cultivars, conducting simple statistics (e.g., mean separation, $t$ test), finding cultivar data to make recommendations to stakeholders (e.g., if you are in extension or a similar role), and finding the 
Table 4. Estimation results from a system of ordered probit models for different features of a modern relational turfgrass cultivar performance database management system regressed on respondents' demographics, occupations, and familiarity of online data source.

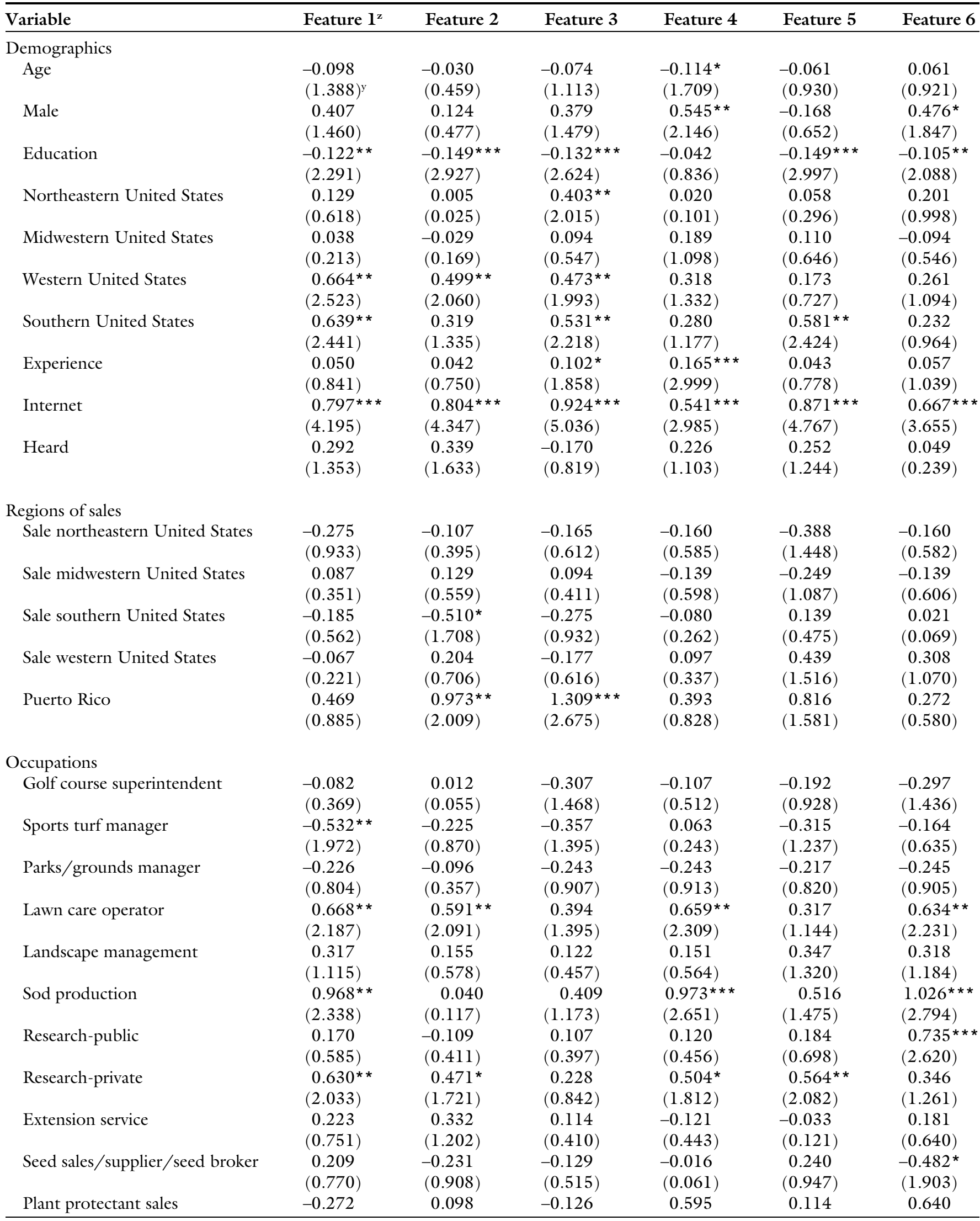


Table 4. (Continued) Estimation results from a system of ordered probit models for different features of a modern relational turfgrass cultivar performance database management system regressed on respondents' demographics, occupations, and familiarity of online data source.

\begin{tabular}{|c|c|c|c|c|c|c|}
\hline Variable & Feature $1^{\mathrm{z}}$ & Feature 2 & Feature 3 & Feature 4 & Feature 5 & Feature 6 \\
\hline Sales & -0.449 & -0.181 & -0.468 & -0.454 & -0.102 & -0.105 \\
\hline \multirow[t]{2}{*}{ Lawn and garden supply } & 0.231 & -0.134 & 0.319 & -0.668 & -0.328 & -0.070 \\
\hline & $(0.440)$ & $(0.272)$ & $(0.631)$ & $(1.308)$ & $(0.667)$ & $(0.140)$ \\
\hline Homeowner & 0.354 & 0.299 & $0.685^{* *}$ & 0.377 & 0.197 & $0.501 *$ \\
\hline & $(1.738)$ & $(0.327)$ & $(0.980)$ & $(0.250)$ & $(1.031)$ & $(0.144)$ \\
\hline \multirow[t]{2}{*}{ Property manager } & -0.532 & -0.356 & -0.354 & -0.517 & $-0.534^{*}$ & -0.087 \\
\hline & $(1.573)$ & $(1.044)$ & $(1.077)$ & $(1.589)$ & $(1.664)$ & $(0.266)$ \\
\hline \multirow[t]{2}{*}{ City or county administrator } & -0.088 & -0.642 & -0.201 & -0.382 & -0.143 & -0.018 \\
\hline & $(0.114)$ & $(0.820)$ & $(0.266)$ & $(0.509)$ & $(0.189)$ & $(0.024)$ \\
\hline
\end{tabular}

${ }^{\mathrm{z}}$ The dependent variables are the features summarized in Table 2 : Feature 1 = find cultivars that have performed well under environmental stress conditions; Feature 2 = identify turfgrass seed options for a specific site based on site conditions; Feature $3=$ find data on turfgrasses for use in a seeding project; Feature $4=$ input the data for cultivars listed in a mixture, the site purpose, and site conditions to determine if this mixture should be recommended for your location/purpose/conditions; Feature $5=$ compare turfgrasses across different National Turfgrass Evaluation Program tests by using standard cultivars and statistics; Feature $6=$ find if a cultivar is currently sold commercially and where to purchase.

${ }^{\mathrm{y}}$ Absolute $t$ statistics in parentheses: ** ${ }^{*}$ significant at the $1 \%$ level; ** significant at the $5 \%$ level; * significant at the $10 \%$ level.

experimental name under which a named cultivar was tested initially (Table 2).

Table 3 presents the summary statistics for users' attitudes toward other important aspects of the NTEP database. More than $84 \%$ of respondents used the Internet to find information on turfgrass performance and $\approx 87 \%$ had heard of the NTEP dataset before this survey. Although $>81 \%$ of respondents had visited the NTEP website at some point before taking the survey, the average frequency of visits was reported as less than once per year (only when needed), and most of them had one or a few visits (Table 3 ).

Seventy-nine percent of the respondents found turfgrass mixture information to be important (Table $3)$. Forty-six percent of the respondents would like the new database to provide a better format of analyzed data output, and $23 \%$ wanted increased speed for data availability ( $\mathrm{Ta}-$ ble 3 ). The median wait time that respondents were willing to endure is $\approx \mathrm{l}$ to $5 \mathrm{~min}$. More than $86 \%$ of the participants would like to download the data if the option is provided. The desire for rapid access lines up with a previous study by Kozub et al. (2000), who suggested that a database for breeding research programs should allow for easy and efficient access.

More than two-thirds of the respondents were familiar with the NTEP website and $\approx 45 \%$ were familiar with geographic information systems (GIS), only $12 \%$ and $5 \%$ of them were familiar with SQL (a language used to communicate with a database) and the codebook from the NTEP website that defines the codes that are used in data reporting, respectively (Table 3 ). As for data options, $34 \%$ of the respondents thought the annual analyzed data would increase their use of a new turfgrass cultivar performance database and $30 \%$ would prefer raw data available for download soon after data collection, together with an annual analyzed data report (Table 3 ). The most preferred query interface was a web-form followed by GIS or a map-based interface. Fewer than $3 \%$ of respondents preferred an SQL interface (Table 3 ), which is not surprising given their lack of knowledge of the language. Most respondents preferred output format in both tables and maps, and $42 \%$ of users desired to download the data into other software.

ESTIMATION RESULTS FROM ORDERED PROBIT MODELS. With 16 dependent variables potentially correlated, we used a system of ordered probit models to identify the critical factors affecting respondents' preference for different usage of the new turfgrass database. The results for 16 dependent variables are presented in Tables 4 to Table 6 . The dependent variables are the features of the NTEP database discussed in Table 2. In general, we found that more educated individuals were less likely to use the NTEP for most of the discussed features. Compared with those who never searched turfgrass information on the Internet, individuals who searched the Internet to find turfgrass information rated all of the presented features as more important, significant at the $1 \%$ level. Age had no significant effects on attitudes toward different data usage, whereas years of experience, being male, and living in different regions had significant effects on some features. Occupation affected individuals' attitudes toward various features quite differently.

Specifically, in Table 4 we found that lawn care managers, sod producers, and respondents who live in the western and the southern United States considered finding information on top-performing cultivars under environmentally stressed conditions as important, but sports turf managers and property managers cared less about turfgrass performance 
Research Reports

Table 5. Estimation results from a system of ordered probit models for different features of a modern relational turfgrass cultivar performance database management system regressed on respondents' demographics, occupations, and familiarity of online data source.

\begin{tabular}{|c|c|c|c|c|c|}
\hline Variable & Feature $7^{z}$ & Feature 8 & Feature 9 & Feature 10 & Feature 11 \\
\hline \multicolumn{6}{|l|}{ Demographics } \\
\hline \multirow[t]{2}{*}{ Age } & -0.051 & -0.067 & 0.058 & -0.055 & 0.052 \\
\hline & $(0.779)^{\mathrm{y}}$ & $(1.025)$ & $(0.874)$ & $(0.835)$ & $(0.788)$ \\
\hline \multirow[t]{2}{*}{ Male } & $0.450^{*}$ & 0.349 & 0.226 & -0.102 & -0.013 \\
\hline & $(1.762)$ & $(1.384)$ & $(0.882)$ & $(0.398)$ & $(0.048)$ \\
\hline Education & $-0.217^{* * *}$ & $-0.115^{* *}$ & $-0.087^{*}$ & $-0.157 * * *$ & -0.010 \\
\hline Northeastern United States & $(1.360)$ & $(0.804)$ & $(0.355)$ & $(1.190)$ & $(1.066)$ \\
\hline \multirow[t]{2}{*}{ Midwestern United States } & 0.192 & 0.172 & -0.032 & 0.068 & -0.243 \\
\hline & $(1.126)$ & $(1.013)$ & $(0.187)$ & $(0.400)$ & $(1.421)$ \\
\hline \multirow[t]{2}{*}{ Western United States } & $0.623 * * *$ & $0.471 * *$ & 0.144 & 0.072 & 0.206 \\
\hline & $(2.576)$ & $(2.005)$ & $(0.608)$ & $(0.305)$ & $(0.858)$ \\
\hline Southern United States & 0.344 & 0.343 & 0.264 & -0.080 & -0.074 \\
\hline \multirow[t]{2}{*}{ Internet } & $0.543^{* * *}$ & $0.696^{* * *}$ & $0.785 * * *$ & $0.583^{* * *}$ & $0.668 * * *$ \\
\hline & $(3.010)$ & $(3.859)$ & $(4.311)$ & $(3.222)$ & $(3.691)$ \\
\hline \multirow[t]{2}{*}{ Heard } & 0.226 & 0.229 & 0.468 ** & 0.096 & 0.131 \\
\hline & $(1.104)$ & $(1.138)$ & $(2.294)$ & $(0.470)$ & $(0.645)$ \\
\hline \multirow[t]{2}{*}{ Sale northeastern United States } & -0.382 & -0.236 & -0.436 & 0.139 & -0.360 \\
\hline & $(1.383)$ & $(0.888)$ & $(1.616)$ & $(0.525)$ & $(1.376)$ \\
\hline \multirow[t]{2}{*}{ Sale midwestern United States } & -0.146 & $-0.379^{*}$ & -0.089 & -0.339 & 0.058 \\
\hline & $(0.627)$ & $(1.655)$ & $(0.387)$ & $(1.496)$ & $(0.257)$ \\
\hline \multirow[t]{2}{*}{ Sale southern United States } & 0.316 & $0.499 *$ & 0.406 & 0.029 & 0.188 \\
\hline & $(1.030)$ & $(1.669)$ & $(1.353)$ & $(0.098)$ & $(0.655)$ \\
\hline \multirow[t]{2}{*}{ Sale western United States } & 0.440 & -0.019 & 0.670 ** & 0.365 & 0.050 \\
\hline & $(1.521)$ & $(0.067)$ & $(2.332)$ & $(1.290)$ & $(0.173)$ \\
\hline & $(0.375)$ & $(0.449)$ & $(0.122)$ & $(0.815)$ & $(1.545)$ \\
\hline Parks/grounds manager & -0.259 & -0.329 & -0.377 & 0.179 & -0.429 \\
\hline & $(0.974)$ & $(1.250)$ & $(1.416)$ & $(0.674)$ & $(1.637)$ \\
\hline Lawn care operator & 0.437 & $0.510^{*}$ & 0.150 & $0.755^{* * *}$ & 0.226 \\
\hline & $(1.529)$ & $(1.815)$ & $(0.536)$ & $(2.698)$ & $(0.828)$ \\
\hline Landscape management & $0.519^{*}$ & 0.074 & 0.403 & -0.000 & -0.222 \\
\hline & $(1.939)$ & $(0.283)$ & $(1.535)$ & $(0.000)$ & $(0.861)$ \\
\hline Sod production & 0.727 ** & 0.403 & $0.630^{*}$ & $0.714^{* *}$ & 0.111 \\
\hline & $(2.064)$ & $(1.205)$ & $(1.813)$ & $(2.077)$ & $(0.331)$ \\
\hline Research-public & 0.052 & 0.225 & $0.714^{* * *}$ & $0.963^{* * *}$ & 0.237 \\
\hline & $(0.198)$ & $(0.863)$ & $(2.640)$ & $(3.603)$ & $(0.881)$ \\
\hline Research-private & $0.545^{* *}$ & $0.658 * *$ & $0.793^{* * *}$ & $0.532 *$ & $0.591 * *$ \\
\hline & $(1.971)$ & $(2.430)$ & $(2.834)$ & $(1.937)$ & $(2.160)$ \\
\hline Extension service & 0.137 & 0.224 & -0.063 & -0.035 & $0.495^{*}$ \\
\hline & $(0.510)$ & $(0.834)$ & $(0.231)$ & $(0.130)$ & $(1.768)$ \\
\hline Seed sales/supplier/seed broker & 0.054 & 0.184 & -0.360 & -0.162 & $0.419^{*}$ \\
\hline & $(0.215)$ & $(0.744)$ & $(1.421)$ & $(0.650)$ & $(1.659)$ \\
\hline Plant protectant sales & 0.316 & 0.397 & 0.583 & 0.469 & 0.443 \\
\hline & $(0.817)$ & $(1.058)$ & $(1.482)$ & $(1.232)$ & $(1.159)$ \\
\hline Sales & $-0.741 * *$ & -0.377 & $-0.540^{*}$ & -0.357 & -0.063 \\
\hline
\end{tabular}

(Continued on next page) 
Table 5. (Continued) Estimation results from a system of ordered probit models for different features of a modern relational turfgrass cultivar performance database management system regressed on respondents' demographics, occupations, and familiarity of online data source.

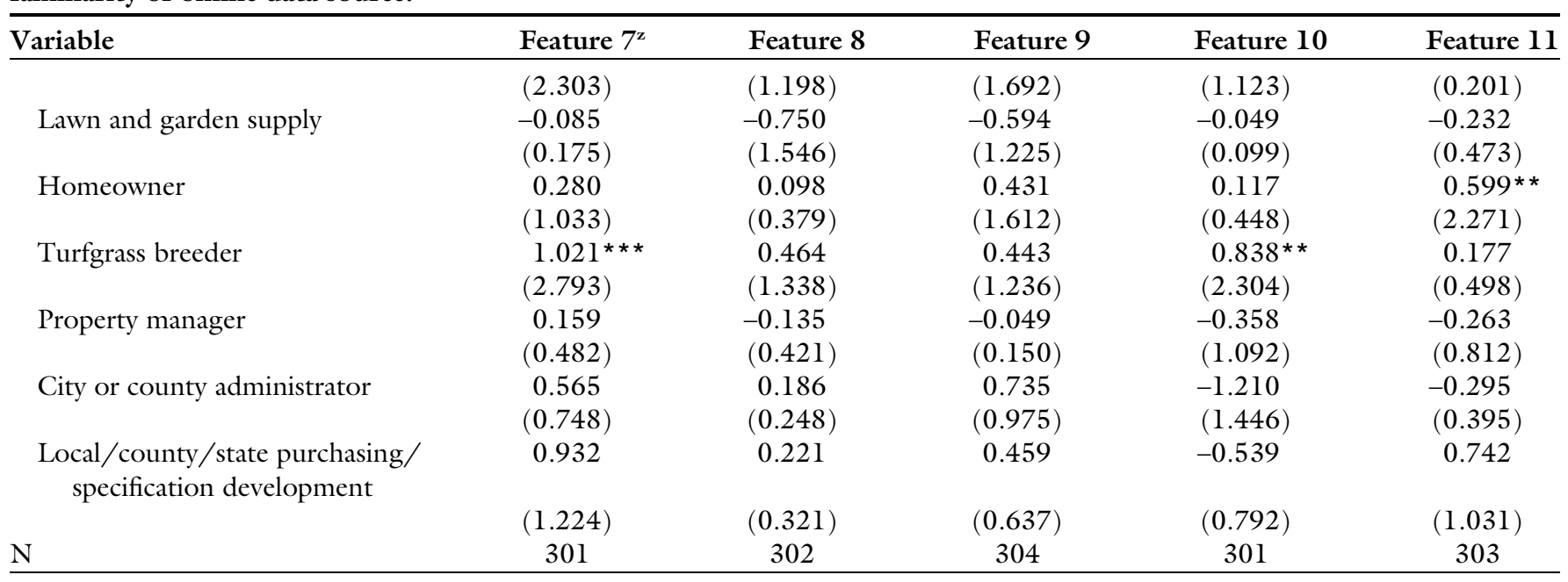

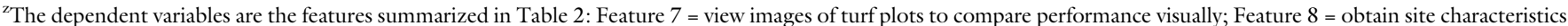
for National Turfgrass Evaluation Program locations; Feature $9=$ search the database to determine general information about a cultivar; Feature $10=$ conduct meta-analysis of large data sets to answer a research question; Feature $11=$ find cultivar data to make recommendations to customers who purchase seed.

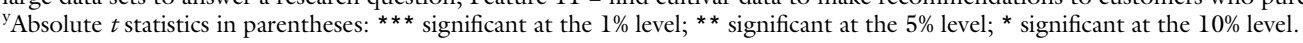

under stressed conditions. Lawn care operators and respondents from the western United States were more likely to care about identifying turfgrass seed options for a specific site based on site conditions, whereas those who manage turfgrass in the southern United States cared less about this feature. This likely is because most warm-season turfgrasses used in the southern United States are established vegetatively by sod, whereas cool-season grasses used in the northern United States are most commonly established by seed (Christians et al., 2017). Homeowners and local/county/state purchasing people were willing to use the database to find information on turfgrasses in a seeding project. People in the western United States, the southern United States, and those with a targeted region in Puerto Rico also thought of this information as useful. More experienced male respondents, lawn care operators, and sod producers cared about the information on mixtures of cultivars for different site purpose, whereas this information was not as valuable to property managers. Private researchers and individuals who live in the southern United States cared about the comparisons of turfgrasses across different NTEP tests, whereas property managers were less likely to care about this feature. Male respondents, sod producers, public researchers, and homeowners wanted to find information on whether a cultivar is currently sold commercially and where to purchase, but seed sales/suppliers had no such needs because they already have enough knowledge on what is in the market.

Results from Table 5 suggested that lawn care operators, private researchers, together with more experienced respondents and those who lived in the western United States, had a preference to obtain site characteristics for NTEP testing locations (e.g., soil test information, weather data) Researchers and homeowners, and those who have heard of the NTEP website rated the general information of a cultivar as useful, whereas seed sales/suppliers/seed brokers and sales did not value this information. Private researchers, extension specialists, and homeowners wanted to find cultivar data to make recommendations for purchasing seed, whereas golf course superintendent and parks/grounds managers were less likely need such information.

Lawn care operators, researchers, extension specialists, and homeowners desired endophyte infection information of tested cultivars. Respondents with their targeted regions in the northeastern United States and the western United States had similar needs. Researchers in both public and private sectors and participants with more years of turfgrass experience were more likely to conduct simple statistical analysis. More experienced respondents, researchers, and extension specialists needed the turfgrass data to make recommendations to stakeholders. Researchers and plant protectant salespersons would like to find the experimental name under which a named cultivar was originally tested. Private researchers and homeowners were more likely to care about the feature to compare differences in average seed size within and between species.

Homeowners would like a new turfgrass cultivars performance database to provide general information about cultivars and comparison of average seed size within and between species; they also desire endophyte infection information and information about where to purchase seed of particular cultivars.

Compared with nonresearchers, researchers needed most of the features, except for some applied usages, such as finding cultivars for specific conditions. Extension specialists, on the other hand, had stronger needs for information on cultivar data and endophyte infection to make recommendations to customers and stakeholders.

Breeders would like to have images of turf plots to compare performance visually, and they would like large data sets to conduct meta-analyses to answer research questions. Sod producers had similar needs compared 
Table 6. Estimation results from a system of ordered probit models for different features of a modern relational turfgrass cultivar performance database management system regressed on respondents' demographics, occupations, and familiarity of online data source.

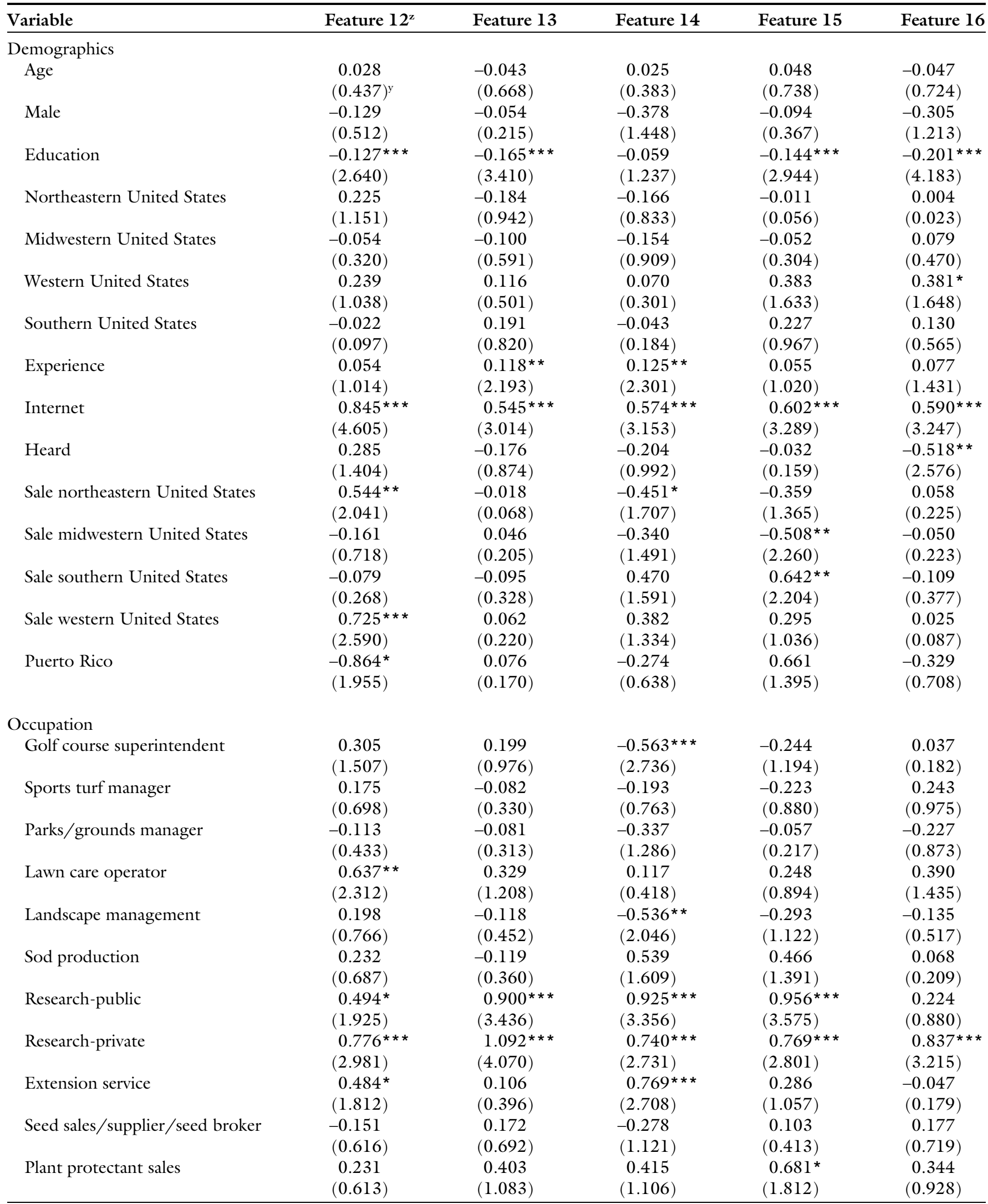

(Continued on next page) 
Table 6. (Continued) Estimation results from a system of ordered probit models for different features of a modern relational turfgrass cultivar performance database management system regressed on respondents' demographics, occupations, and familiarity of online data source.

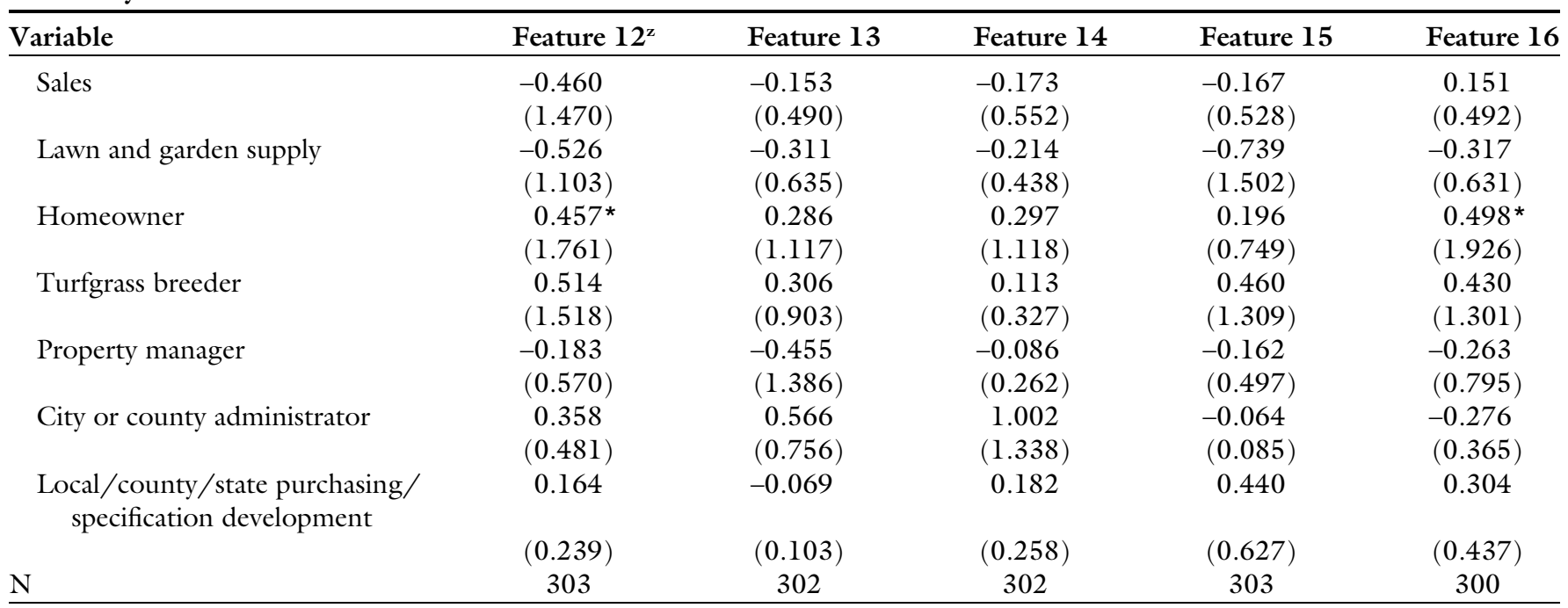

${ }^{\mathrm{z}}$ The dependent variables are the features summarized in Table 2: Feature 12 = find endophyte infection information of tested cultivars; Feature 13 = conduct simple statistics (e.g., mean separation, $t$ test); Feature $14=$ find cultivar data to make recommendations to stakeholders; Feature $15=$ find the experimental name under which a named cultivar was originally tested; Feature $16=$ compare differences in average seed size within and between species.

yAbsolute $t$ statistics in parentheses: ${ }^{* *}$ significant at the $1 \%$ level; ${ }^{* *}$ significant at the $5 \%$ level; ${ }^{*}$ significant at the $10 \%$ level.

with breeders, but they also would like turfgrass data to be applied in specific seeding projects, such as finding places to purchase seeds of a particular cultivar, finding cultivars that perform well under stressed environmental conditions, and finding if a mixture could be recommended for a specific location/ purpose/condition.

Lawn care operators had similar needs as sod producers. They needed information on both the cultivars and the site characteristics to find the best cultivars for specific site conditions, together with information on endophyte infection. Seed sales, suppliers, and seed brokers cared less about general information or images of turf cultivar, and as discussed earlier, they did not value information on the availability of turf cultivars in the market. Managers (golf course superintendents, sports turf managers, park/ground managers, landscape managers, and property managers), on the other hand, rated the information from the NTEP database as less useful.

\section{Conclusions}

The results in this study can be useful for developing a new turfgrass cultivar performance database and will benefit turfgrass consumers, researchers, breeders, and growers, as well as distributors by providing more convenient and useful information for different end users. The findings suggest that turfgrass consumers need the new database to provide information on identifying turfgrass options that are resource efficient and endophyte resistant. Turfgrass breeders, researchers, and extension specialists would use the new turfgrass cultivar performance database to compare different turfgrasses cultivars to do further analysis.

Although most of our respondents have heard of the NTEP data, the frequency with which they visit the NTEP website is quite low, indicating that the NTEP website is in fact underused. Half of the respondents we surveyed wanted the NTEP data delivered to the public in a better format. Therefore, developing a new turfgrass database in a user-friendly format, perhaps as a web-form or using a map-based interface, could help users from multiple parties to get more accurate turfgrass knowledge as conveniently as they need.

The most in need features of the new turfgrass database include information to identify environmental stress tolerant cultivars and to find best-adapted turfgrass seeds for different projects. The information on turfgrass mixtures and blends is also important. Turfgrass seeds consumers, such as lawn care operators, sod producers, and homeowners, all find these features important. As Yue et al. (2017a) suggested, trust plays an essential role in the use of product information, but turfgrass consumers think most of the Internet sources are not trustworthy. Developing a new database and providing networks between the third-party authorities can make existing databases more useful and trustworthy for consumers. Therefore, providing analyzed data on evaluations and recommendations of certain cultivars under localized environmental conditions can help consumers to make better seed purchasing decisions. With the availability of more map-based turfgrass data, consumers can use their location to get the needed environmental information and identify the best-suited cultivars for their lawn.

At the same time, the new database can provide a platform for turfgrass researchers, extension personnel, and breeders to interact with stakeholders. Although consumers can get valuable information about specific cultivars when purchasing grass seed, researchers and breeders can get feedback from turfgrass consumers, which motivate them to develop turfgrass cultivars with traits more suitable for market needs.

In conclusion, this study provides insights on how to develop a turfgrass database by investigating the usages and needs from end users of the current NTEP data. With users 
from different occupations desiring different features, programmers can develop the new database step by step, focusing on the most essential features first, and extend to fulfill the needs of all user groups. With growing needs for turfgrass knowledge among consumers, providing consumers with accurate evaluations of the adaptability of different cultivars can help consumers make better choices, and benefit society by improving turf quality with fewer inputs. The new relational management system database can simplify consumer queries on the NTEP data and provide useful information that can result in more sustainable home and public landscapes. An increase in consumer use of turfgrass performance data also can provide information for breeders to focus on developing turfgrasses with improved traits that better align with consumer preferences; for example, consumers in temperate climates have shown a desire for lower-input traits (Yue et al., 2017b), but the demand for these traits has not translated into greater low-input turfgrass sales. In the future, a functional database will help turfgrass consumers to better judge which cultivar(s) to use for seeding and renovation projects, thereby increasing the use of improved, low-input turfgrass cultivars.

\section{Literature cited}

Beard, J. and R. Green. 1994. The role of turfgrasses in environmental protection and their benefits to humans. J. Environ. Qual. 23(3):1-16.

Beddow, J., E. Jones, and D. Lamie. 2001. The economics of turfgrass in the commonwealth of Virginia. Virginia Agr. Expt. Sta. Bul. 1.

Christians, N.E., A.J. Patton, and Q.D. Law. 2017. Fundamentals of turfgrass management. Wiley, Hoboken, NJ.

Greene, W.H. and D.A. Hensher. 2010 Modeling ordered choices: A primer. Cambridge Univ. Press, New York, NY.

Kozub, J.G., D.R. Lynch, G.C. Kozub, L.M. Kawchuk, and D.K. Fujimoto. 2000. A relational database system for potato breeding programs. Amer. J. Potato Res. 77(2):95-101.

Martini, N.F., K.C. Nelson, S.E. Hobbie, and L.A. Baker. 2015. Why 'Feed the Lawn'? Exploring the influences on residential turf grass fertilization in the Minneapolis-Saint Paul metropolitan area. Environ. Behav. 47(2):158-183.

Meyer, W.A., L. Hoffman, and S.A. Bonos. 2017. Breeding cool-season turfgrass cultivars for stress tolerance and sustainability in a changing environment. Int. Turfgrass Soc. Res. J. 13(1):3-10.

Milesi, C., S.W. Running, C.D. Elvidge, J.B. Dietz, B.T. Tuttle, and R.R. Nemani. 2005. Mapping and modeling the biogeochemical cycling of turf grasses in the United States. Environ. Mgt. 36(3):426438.

Monaghan, P., S. Hu, G. Hansen, E. Ott, C. Nealis, and M. Morera. 2016. Balancing the ecological function of residential stormwater ponds with homeowner landscaping practices. Environ. Mgt. 58(5):843856.
Patton, A.J., L. Trenholm, and F.C. Waltz. 2013. Turfgrass extension and outreach programming, p. 147-177. In J.C. Stier, B.P. Horgan, and S.A. Bonos (eds.). Turfgrass: Biology, use, and management. Agron. Monogr. 56. Amer. Soc. Agron., Crop Sci. Soc. Amer., Soil Sci. Soc. Amer., Madison, WI.

Robbins, P. and T. Birkenholtz. 2003. Turfgrass revolution: Measuring the expansion of the American lawn. Land Use Policy 20(2):181-194.

Robbins, P. and J.T. Sharp. 2003. Producing and consuming chemicals: The moral economy of the American lawn. Econ. Geogr. 79(4):425-451.

Yue, C., R.K. Gallardo, J.J. Luby, A.L. Rihn, J.R. McFerson, V. McCracken, T. Gradziel, K. Gasic, G.L. Reighard, J. Clark, and A. Iezzoni. 2010. An evaluation of U.S. peach producers' trait prioritization: Evidence from audience surveys. HortScience 49:1309-1314.

Yue, C., J. Wang, E. Watkins, S. Bonos, K. Nelson, J.A. Murphy, W. Meyer, and B.P. Horgan. 2017a. Consumer preferences for information sources of turfgrass products and lawn care. Agron. J. 109(4):17261733.

Yue, C., J. Wang, E. Watkins, S.A. Bonos, K.C. Nelson, J.A. Murphy, W.A. Meyer, and B.P. Horgan. 2017 b. Heterogeneous consumer preferences for turfgrass attributes in the United States and Canada. Can. J. Agr. Econ. 65(3):347-383. 